\title{
Editorial
}

\section{Addressing health inequalities in health impact assessment}

The United Kingdom has unacceptable inequalities in health and life expectancy by socioeconomic status, ethnic group and gender. ${ }^{1}$ Many of these differences have widened over the past two decades. This means, for example, that over 17000 fewer 20 to 64 year old men would die each year if all adult men shared the death rates of social classes I and II. ${ }^{1}$

The Acheson report reviewed the evidence on inequalities in health in England and concluded that they related primarily to social inequalities in health determinants like income, education, employment and the material environment. ${ }^{1}$ The report made a series of recommendations to reduce inequalities by acting on these determinants. It also recognised a need to try to prevent future inequalities, by ensuring that government policies improved the position of the worst off people. Its first recommendation-one of three given priority among Acheson's 39 recommendations - proposed that: "as part of health impact assessment, all policies likely to have a direct or indirect effect on health should be evaluated in terms of their impact on health inequalities".

Health impact assessment is a decision making tool that has been defined as "the estimation of the effects of a specified action on the health of a defined population". Potential health impacts are identified by considering how a proposed policy or project may affect the determinants of health. ${ }^{23}$ Assessments should make explicit in what ways a proposal will affect health and which groups in the population will bear these health impacts. ${ }^{4}$ This can help compare options, and suggest recommendations to maximise health benefit from a proposal. Health impact assessment is usually used to assess a policy, programme or project that does not have health as its primary objective. ${ }^{56}$ It could also be applied to activities that are intended to improve health, as a way of identifying any unintended effects or side effects, and maximising the resultant health gain.

The Liverpool Public Health Observatory recently held an international seminar to discuss how to address health inequalities within health impact assessment. Two approaches in particular were discussed: selectively assessing potential health impacts of policies or projects on disadvantaged groups, and assessing the differential distribution of impacts across the whole population. Participants also debated whether inequalities should be emphasised in all health impact assessments, or whether a separate process of "health inequalities impact assessment" as implied by the Acheson report's recommendation, is required.

Many seminar participants felt that all health impact assessments should be concerned with inequalities because equality of income, status or opportunity is an important determinant of health. There is good evidence that more equal societies have better health overall. ${ }^{7}$ Equity is also a value, which arguably should underpin health impact assessment and inform the whole process. ${ }^{3}$ There may be trade offs between improving average health, improving the health of the most disadvantaged people, and reducing inequalities in health. ${ }^{8}$ Health impact assessment should make these trade offs explicit; restricting inequalities to a separate assessment would make them less so. The seminar's conclusions were that all health impact assessment methods and procedures should focus on health inequalities, explicitly considering both impacts on disadvantaged groups and the distribution of impacts across the population.

Disadvantaged groups are often exposed to more health hazards (environmental inequity) and are also more susceptible. ${ }^{9}$ The argument for selectively focusing on these groups in health impact assessment is to formulate recommendations to ensure that the most vulnerable people are protected from avoidable harm and obtain maximum benefit. However, identifying the groups who may be disadvantaged by a proposal may be difficult at the start of an assessment. ${ }^{10}$ In addition, such a "high risk"' approach does not assess the overall health impact on the whole population and fails to show how proposals may increase or reduce health inequalities across the population.

Inequalities in health do not relate solely to the most disadvantaged people. There are differences in health across the social spectrum. ${ }^{11}$ The alternative approach is to estimate potential health impacts on the range of groups in a population, compare these impacts and assess potential changes in the distribution of each determinant. This will identify potential "winners" and "losers" and also whether a proposal is likely to increase or reduce health inequalities over the population. Recommendations may still give priority to the most vulnerable people.

The way health impact assessment is carried out may also be important in improving equity in health. Health impact assessment can be done in a participatory way, which involves people and allows them to express their views. ${ }^{23}$ This can itself raise self esteem, particularly in disadvantaged communities, in addition to the benefits gained from addressing "lay" perspectives. ${ }^{12}$

Explicitly considering health inequalities in health impact assessment should bring several important benefits. It should raise awareness of inequalities in health and of their causes; it should lead to better decisions that help prevent health inequalities arising in future; and it should produce more transparent and accountable decision making.

Lothian Health, Edinburgh

MARGARET DOUGLAS

ALEX SCOTT-SAMUEL

Liverpool Public Health Observatory, Department of Public Health, University of Liverpool, Whelan Building, Quadrangle, Liverpool $L 693 G B, U K$

Funding: the seminar was funded by the Department of Health (London) Conflicts of interests: none.

1 Acheson D (Chairman). Independent inquiry into inequalities in health. London: The Stationery Office, 1998. http://www.doh.gov.uk/ih/ih.htm (accessed 6 March 2001)

2 Scott-Samuel A, Birley M, Ardern K. The Merseyside guidelines for health impact assessment. Liverpool: Merseyside Health Impact Assessment Steering Group/Liverpool Public Health Observatory, 1998.

3 World Health Organisation European Centre for Health Policy. Health impact assessment: main concepts and suggested approach. Gothenburg consensus paper. Brussels: European Centre for Health Policy, 1999. http:// www.who.dk/hs/ECHP/attach/gothenburg.htm (accessed 6 March 2001)

4 Scottish Needs Assessment Programme. Health impact assessment: piloting the process. Glasgow: Scottish Needs Assessment Programme, 2000. http:/ www.gla.ac.uk/Inter/OPHIS/PDF/hia.pdf (accessed 6 March 2001)

5 Lock K. Health impact assessment. BMF 2000;320:1395-98.

6 Mcintyre L, Petticrew M. Methods of health impact assessment: a literature review. Occasional paper no 2. Glasgow: MRC Social and Public Health review. Occasional paper no 2. Glasgow: MRC Social and Public Health Occasional-Papers/OP-002.pdf (accessed 6 March 2001)

7 Wilkinson RG. Unhealthy societies: the afflictions of inequality. London: Wilkinson RG. Unhe
Routledge, 1996. 
8 Rose G. The strategy of preventive medicine. Oxford: Oxford University Press,

9 Whitehead M, Burstrom B, Diderichsen F. Social policies and the pathways Whitehead $M$, Burstrom B, Diderichsen F. Social policies and the pathways
to inequalities in health: a comparative analysis of lone mothers in Britain and Sweden. Soc Sci Med 2000;50:255-70.

10 Scottish Needs Assessment Programme. Health impact assessment of the City of Edinburgh Council's urban transport strategy. Glasgow: Scottish Needs
Assessment Programme, 2000, http://www.gla.ac.uk/Inter/OPHIS/PDF/ hiatrans. PDF (accessed 6 March 2001)

11 Marmot MG, Davey Smith G, Stansfield S, et al. Health inequalities among British civil servants: the Whitehall II study. Lancet 1991;337: among Briti

12 Macaulay AC, Commanda LE, Freeman WL, et al. Participatory research maximises community and lay involvement. BMF 1999;319:774-8.

\section{The fECH gallery}

\section{The many causes of human despair, La Ramblas, Barcelona}

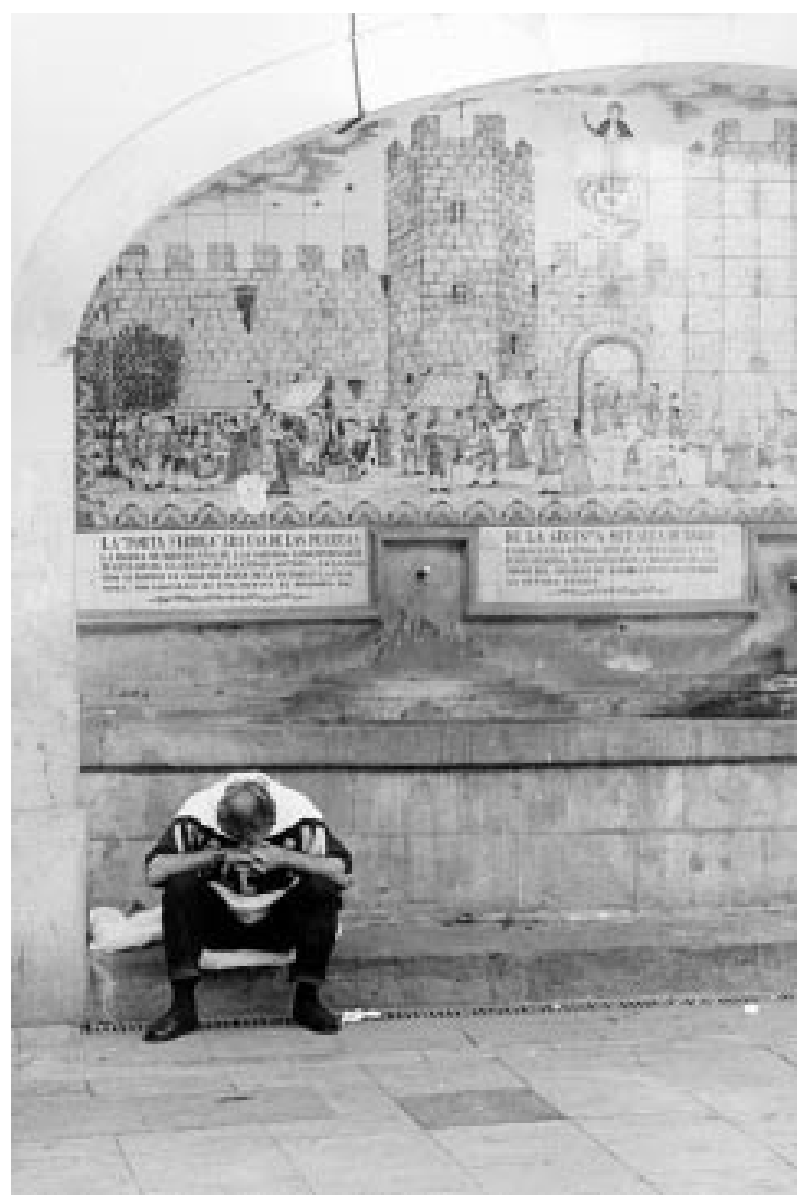

Whether it was homelessness, addiction, marital disharmony, physical ill health, bereavement, stressful work, or the loss of a football match that caused this man's despair, the observer cannot tell. What is certain though, is that he was equally as oblivious of the many passers by, as they were of him.

RICHARD D NEAL

Centre for Research in Primary Care, Nuffield Institute for Health, University of Leeds, 71-75 Clarendon Street, Leeds LS2 9PL, UK (r.d.neal@leeds.ac.uk) 